\title{
Axonal regeneration of retinal ganglion cells after optic nerve pre-lesions and attachment of normal or pre-degenerated peripheral nerve grafts
}

\author{
SI-WEI YOU, ${ }^{1,2}$ KULDIP S. BEDI, ${ }^{3}$ HENRY K. YIP, ${ }^{1}$ AND KWOK-FAI SO ${ }^{1}$ \\ ${ }^{1}$ Department of Anatomy, The University of Hong Kong, Hong Kong, China \\ ${ }^{2}$ Institute of Neurosciences, The Fourth Military Medical University, Xi' an, China \\ ${ }^{3}$ School of Biomedical Sciences, University of Queensland, St Lucia, Australia
}

(Received November 30, 2001; AcCePted August 21, 2002)

\begin{abstract}
Axonal regeneration of retinal ganglion cells (RGCs) into a normal or pre-degenerated peripheral nerve graft after an optic nerve pre-lesion was investigated. A pre-lesion performed 1-2 weeks before a second lesion has been shown to enhance axonal regeneration in peripheral nerves $(\mathrm{PN})$ but not in optic nerves $(\mathrm{ON})$ in mammals. The lack of such a beneficial pre-lesion effect may be due to the long delay (1-6 weeks) between the two lesions since RGCs and their axons degenerate rapidly 1-2 weeks following axotomy in adult rodents. The present study examined the effects of the proximal and distal ON pre-lesions with a shortened delay ( $0-8$ days) on axonal regeneration of RGCs through a normal or pre-degenerated PN graft. The ON of adult hamsters was transected intraorbitally at $2 \mathrm{~mm}$ (proximal lesion) or intracranially at $7 \mathrm{~mm}$ (distal lesion) from the optic disc. The pre-lesioned ON was re-transected at $0.5 \mathrm{~mm}$ from the disc after $0,1,2$, 4, or 8 days and a normal or a pre-degenerated PN graft was attached onto the ocular stump. The number of RGCs regenerating their injured axons into the PN graft was estimated by retrograde labeling with FluoroGold 4 weeks after grafting. The number of regenerating RGCs decreased significantly when the delay-time increased in animals with both the ON pre-lesions (proximal or distal) compared to control animals without an ON pre-lesion. The proximal ON pre-lesion significantly reduced the number of regenerating RGCs after a delay of 8 days in comparison with the distal lesion. However, this adverse effect can be overcome, to some degree, by a pre-degenerated PN graft applied 2, 4, or 8 days after the distal ON pre-lesion enhanced more RGCs to regenerate than the normal PN graft. Thus, in order to obtain the highest number of regenerating RGCs, a pre-degenerated PN should be grafted immediately after an ON lesion.
\end{abstract}

Keywords: Retinal ganglion cell, Optic nerve, Regeneration, Transplantation, Pre-lesion

\section{Introduction}

Pre-lesioning a peripheral nerve (PN) 1-2 weeks before a second lesion has been shown to accelerate axonal regeneration by reducing the initial delay between the second lesion and initiation of axonal regrowth (McQuarrie et al., 1978), or enhancing the elongation rate of regrowing PN axons of rodents (McQuarrie et al., 1977; Wells \& Bernstein, 1978). A similar phenomenon has also been observed in the optic axons of lower vertebrates, such as goldfish (Lanners \& Grafstein, 1980; McQuarrie \& Grafstein, 1981; Reich et al., 1990) and amphibians (Brock, 1978). Such a PN pre-lesion has a greater effect on enhancing the number of regenerating myelinated peripheral axons than a pre-degenerated PN graft, although both the pre-lesion and pre-degenerated PN graft are of importance in influencing axonal regeneration (Hasan

Address correspondence and reprint requests to: Kwok-Fai So, Department of Anatomy, Faculty of Medicine, the University of Hong Kong, 5 Sassoon Road, Hong Kong, China. E-mail: hrmaskf@hkucc.hku.hk et al., 1996). However, no such beneficial effects of a pre-lesion have hitherto been demonstrated in the optic nerve (ON) of adult mammals. The pre-lesion of the adult rat $\mathrm{ON}$ for 2 weeks does not induce the regeneration of retinal axons in the ON (Kiernan, 1985). In addition, the number of regenerating axons from retinal ganglion cells (RGCs) into a PN graft was not increased with a pre-lesion applied to the ON 1-6 weeks before PN grafting (Thanos \& Vanselow, 1989). Nevertheless, crushing of the ON followed immediately attaching a PN graft to the retina via a lesion through the sclera has been shown to shorten the initial delay for retinal axons to regrow into the PN graft (Cho \& So, 1987, 1989), although no reduction of the initial delay was observed if the $\mathrm{ON}$ was pre-lesioned 1 or 2 weeks before the PN grafting.

The interval between the two lesions influences the effects of the pre-lesion ("conditioning lesion"). In the goldfish optic axons, a 2-week period has been found to be the most effective interval for maximal enhancement of axonal outgrowth in vivo (Edwards et al., 1979), whereas an interval as short as 2 days or as long as 28 days resulted in accelerated outgrowth of sensory axonal out- 
growth in rats (Forman et al., 1980). The lack of the beneficial pre-lesion effect in mammalian $\mathrm{ON}$ reported by early studies may be due to the long interval (1-6 weeks) between the two lesions since RGCs (Berkelaar et al., 1994) and their axons degenerate rapidly 7-14 days following axotomy in adult rodents (Zeng et al., 1995). It is possible that if optimal conditions are met, a pre-lesion may enhance axonal regeneration.

Despite these observations, no studies have attempted to examine whether both a pre-lesion of the central nervous system (CNS) axons and the use of a pre-degenerated PN graft can induce the maximal axonal regeneration of axotomized CNS neurons. Thus in this study, we have investigated the effects of an intraorbital (proximal) as well as intracranial (distal) ON pre-lesion with different intervals ( $0-8$ days) between the ON pre-lesion and PN grafting on axonal regeneration of axotomized RGCs in adult hamsters. The effect of pre-degenerated PN grafts on axonal regeneration of axotomized RGCs in the animals with either a distal or proximal ON pre-lesion was also examined. Some of the results have appeared in abstract form (You et al., 1996).

\section{Materials and methods}

A total of 96 adult female hamsters (Mesocricetus auratus, 7-8 weeks old; the Laboratory Animal Unit of Faculty of Medicine, the University of Hong Kong) were used and divided into three groups. These animals were treated in accordance with the principles regarding the care and use of animals adopted by the American Physiological Society and the Society for Neuroscience. All surgical procedures were carried out under sodium pentobarbital (Nembutal, 60 mg/kg body weight; Rhone Merieux Australia Pty Ltd., Australia) anesthesia given by intraperitoneal injection.

\section{Surgical procedures}

Preparation of normal and pre-degenerated PN grafts

The left sciatic nerve was exposed and transected at mid-thigh level. The distal portion of the cut nerve was tied with a 5/0 suture (Mersilk, W595, Ethicon Ltd., UK) and displaced away from the proximal end to ensure that no regenerating axons from the proximal PN stump could grow into the distal nerve stump. Portions of the distal end of these nerves (about $2 \mathrm{~cm}$ ) were harvested either 0 (normal PN graft) or 8 (pre-degenerated PN graft) days after transection and used for grafting as described below.

\section{The control group (Group 1)}

We used two subgroups of animals in our previous study as the control animals for the present study (You et al., 2000). For these control animals, the intraorbital portion of the left ON with its surrounding dura was exposed carefully using a superior temporal approach. The dura was cut longitudinally to expose the actual nerve (Fig. 1A). The ON was transected $0.5 \mathrm{~mm}$ behind the optic disc (Fig. 1B) paying special attention to avoid damaging the retinal blood supply. The ocular ON stump was immediately attached to either a normal $(n=6)$ or a pre-degenerated $(n=6) \mathrm{PN}$ graft (Fig. 1C) using a 10/0 suture (Ethilon, W2814, Ethicon Ltd., UK). The distal end of the PN graft was tied to the connective tissue on the skull and the skin flaps were replaced.

The proximal ON pre-lesion group (Group 2)

The intraorbital portion of the left $\mathrm{ON}$ was exposed (as described above) and transected $2 \mathrm{~mm}$ from the optic disc $(n=24$,
Fig. 1E). The animals were allowed to recover for either 2 or 8 days ( $n=12$ for each time point) from this initial transection. Following this period, the ocular stump was re-exposed and retransected $0.5 \mathrm{~mm}$ from the optic disc (Fig. 1F). Normal ( $n=6$ for each time point) or pre-degenerated ( $n=6$ for each time point) sciatic nerve segments were grafted onto the remaining stump as before (Fig. 1G).

\section{The distal ON pre-lesion group (Group 3)}

The distal ON pre-lesion was prepared in 60 animals by transecting the $\mathrm{ON}$ intracranially at approximately $7 \mathrm{~mm}$ from the optic disc (Fig. 1I) as described previously (You et al., 2000). The animals were allowed to recover for a period of 0 (approximately $20 \mathrm{~min}$ ), 1, 2, 4, or 8 days ( $n=12$ at each time point), respectively. Following this period, the intraorbital part of the same ON was exposed, sectioned $0.5 \mathrm{~mm}$ behind the optic disk (Fig. 1J) and a normal ( $n=6$ for each time point) or pre-degenerated ( $n=6$ for each time point) $\mathrm{PN}$ graft were sutured onto the remaining proximal ON stump (Fig. 1K).

\section{Labeling and counting of regenerating $R G C s$}

After PN transplantation, all animals were allowed to survive for 4 weeks. Three days before they were killed with an overdose of sodium pentobarbital, the PN graft in all animals was exposed and severed at about $0.5 \mathrm{~cm}$ from the attachment site on the skull. A small piece (about $3 \mathrm{~mm}^{3}$ ) of Gelfoam soaked in $6 \%$ FG (Fluorochrome, Inc., Colorado, USA) was introduced to the cut end of the graft to retrogradely label the regenerating RGCs (Fig. 1: Group 1, D, Group 2, H; and Group 3, L). The left retinas were removed without transcardial perfusion, prepared as wholemounts and fixed in 4\% paraformaldehyde (Merck, Germany) in phosphate buffer (0.1 M, pH 7.4; Sigma Chemical Co., St. Louis, MO) for $1 \mathrm{~h}$, rinsed in phosphate-buffered saline $(0.1 \mathrm{M}, \mathrm{pH} 7.4$; Sigma) three times, and mounted in glycerol (Merck, Germany). The FG-labeled RGCs were counted in all the retinas under a fluorescence microscope (Nikon, Model MM-11, Japan) with an interchangeable filter (400 $\mathrm{nm}$ for FG).

\section{Statistical analysis}

The data on the numbers of regenerating RGCs within the control group was analyzed by one-way analysis of variance (ANOVA) to determine if there were any statistically significant differences between the different types of graft. The data on the numbers of regenerating RGCs in the groups where there was a delay between the pre-lesion and placement of the graft was first tested using three-way ANOVA. In this test, the delay-time given for the ON pre-lesion to take effect ( 2 or 8 days), ON pre-lesion site (proximal or distal), and the graft type (normal or pre-degenerated) were used as the factors. In this analysis, the data collected for the 0,1 , and 4 day delay-time points in the distal ON pre-lesion group were ignored for the sake of simplicity. The data collected within the proximal or distal ON prelesion groups were further analyzed using two-way ANOVA with the delay-time $(0,1,2,4$, or 8 days) and graft type (normal or pre-degenerated) as the factors. Post-hoc analysis using TukeyKramer's tests were carried where appropriate. All statistical analyses were performed using SPSS Release 6.0 statistical package (SPSS Inc., Chicago, IL; 1989-1993). 

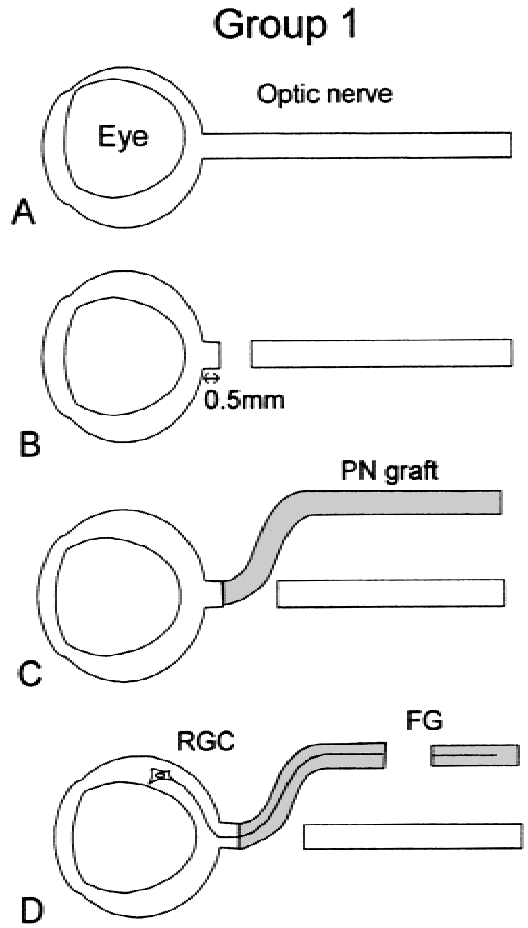
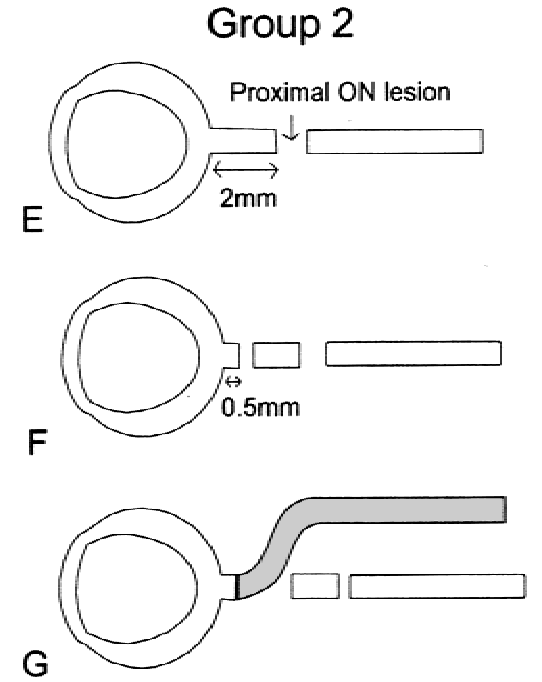

G

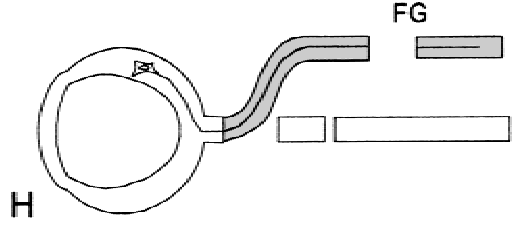

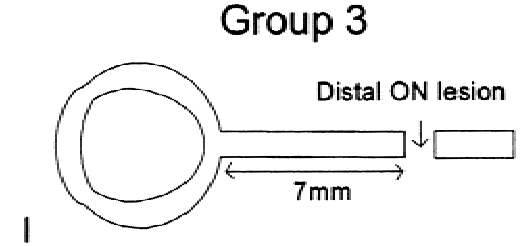
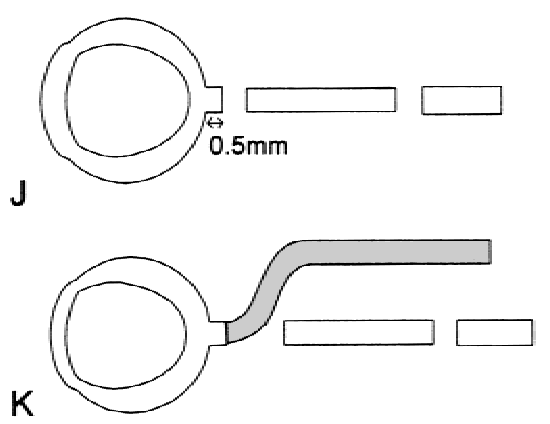

$\mathrm{K}$

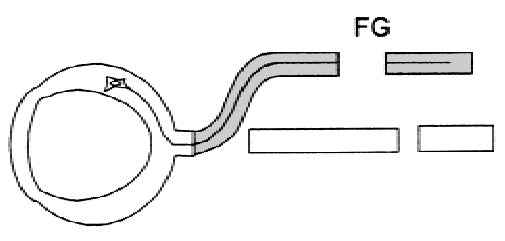

Fig. 1. Schematic diagrams illustrating the left intact $\mathrm{ON}(\mathrm{A})$, intraorbital $\mathrm{ON}$ transection at $0.5 \mathrm{~mm}$ from the optic disc (B), and transplantation of a normal or pre-degenerated PN graft onto the ocular stump of the ON (C) in the control animals. RGCs that regenerated their axons into the PN graft were labeled retrogradely with FG applied to the cut end of the graft severed at about $0.5 \mathrm{~cm}$ from the attachment site (D). Intraorbital ON transection at $2 \mathrm{~mm}$ from the optic disc was used as the proximal ON pre-lesion (E). The same ocular ON stump was transected again intraorbitally at $0.5 \mathrm{~mm}$ from the optic disc (F) and attached with a normal or pre-degenerated PN graft $(\mathrm{G})$. Regenerating RGCs were labeled retrogradely with FG $(\mathrm{H})$. Intracranial ON transection at $7 \mathrm{~mm}$ from the optic disc was performed as the distal ON pre-lesion (I). The intraorbital part of the same ON was sectioned $0.5 \mathrm{~mm}$ from the optic disk (J) and a normal or pre-degenerated PN graft was sutured onto the remaining proximal ON stump (K). FG was applied to retrogradely label the regenerating RGCs (L).

\section{Results}

The number of regenerating RGCs was determined by counting retrogradely FG-labeled RGCs in all retinas. The distribution, density, and general morphology (Figs. 2A \& 2B) of regenerating RGCs were similar to those described previously (Lau et al., 1994; You et al., 2000).

In the control animals which were used in our previous study (You et al., 2000), the results analyzed by one-way ANOVA showed no significant difference $(P=0.9490)$ in the number of regenerating RGCs 4 weeks after grafting between the normal (Mean $\pm \mathrm{SD}=1644 \pm 212)$ and pre-degenerated $(1628 \pm 579) \mathrm{PN}$ grafts (Figs. 2C, 2D, \& 3).

Three-way ANOVA of the data within the proximal and distal ON pre-lesion groups (Groups $2 \& 3$ ) showed significant effects $(P<0.001)$ of all three factors (i.e. the delay-time, ON pre-lesion site, and graft type) as well as significant first-order interactions between the various factors $(P<0.001)$. The second-order interaction term was not statistically significant $(P=0.333)$.

Two-way ANOVA of the data in the proximal ON pre-lesion group (Group 2) showed significant effects of the delay-time $(P<$ $0.001)$ and graft type $(P=0.033)$, although the interaction term was not significant $(P=0.073)$. Post-hoc tests showed that extending the delay-time from 2 days to 8 days had a marked detrimental effect on the numbers of RGCs that were able to regenerate axons into the normal $(P=0.0035)$ or pre-degenerated $(P<0.0001)$ PN graft (Fig. 3A). Although the effect of the graft type was significant $(P=0.033)$ with two-way ANOVA, further analysis by one-way ANOVA detected similar numbers of regenerating RGCs between the animals with the normal and predegenerated PN grafts at both 2- (1116 \pm 557 and $1688 \pm 319$ for the normal and pre-degenerated PN grafts, respectively; $P=$ $0.0539)$ and 8-day $(239 \pm 104$ and $293 \pm 161 ; P=0.5020)$ time points (Fig. 3A). For Group 3 animals with the distal ON prelesion, two-way ANOVA revealed that both the delay-time $(P<$ 0.001) and graft type $(P<0.001)$ as well as the interaction term between these factors $(P=0.001)$ were statistically significant. Post-hoc tests of these data showed that increasing the delay-time from 0 day to 8 days had a steady but marked detrimental effect on the numbers of regenerating RGCs (Figs. 2E, 2F, \& 3B). Furthermore, when animals with different types of PN grafts were compared at the corresponding time points, no significant difference $(P>0.0500)$ was detected at $0(1451 \pm 153$ and $1337 \pm 184$ for the normal and pre-degenerated PN grafts, respectively; $P=$ $0.2703)$ and $1(997 \pm 194$ and $1492 \pm 549 ; P=0.0638)$ day time points (Fig. 3B). When the delay-time further increased, however, the pre-degenerated PN graft induced more RGCs to regenerate at $2(854 \pm 149$ and $1598 \pm 259$ for the normal and pre-degenerated 

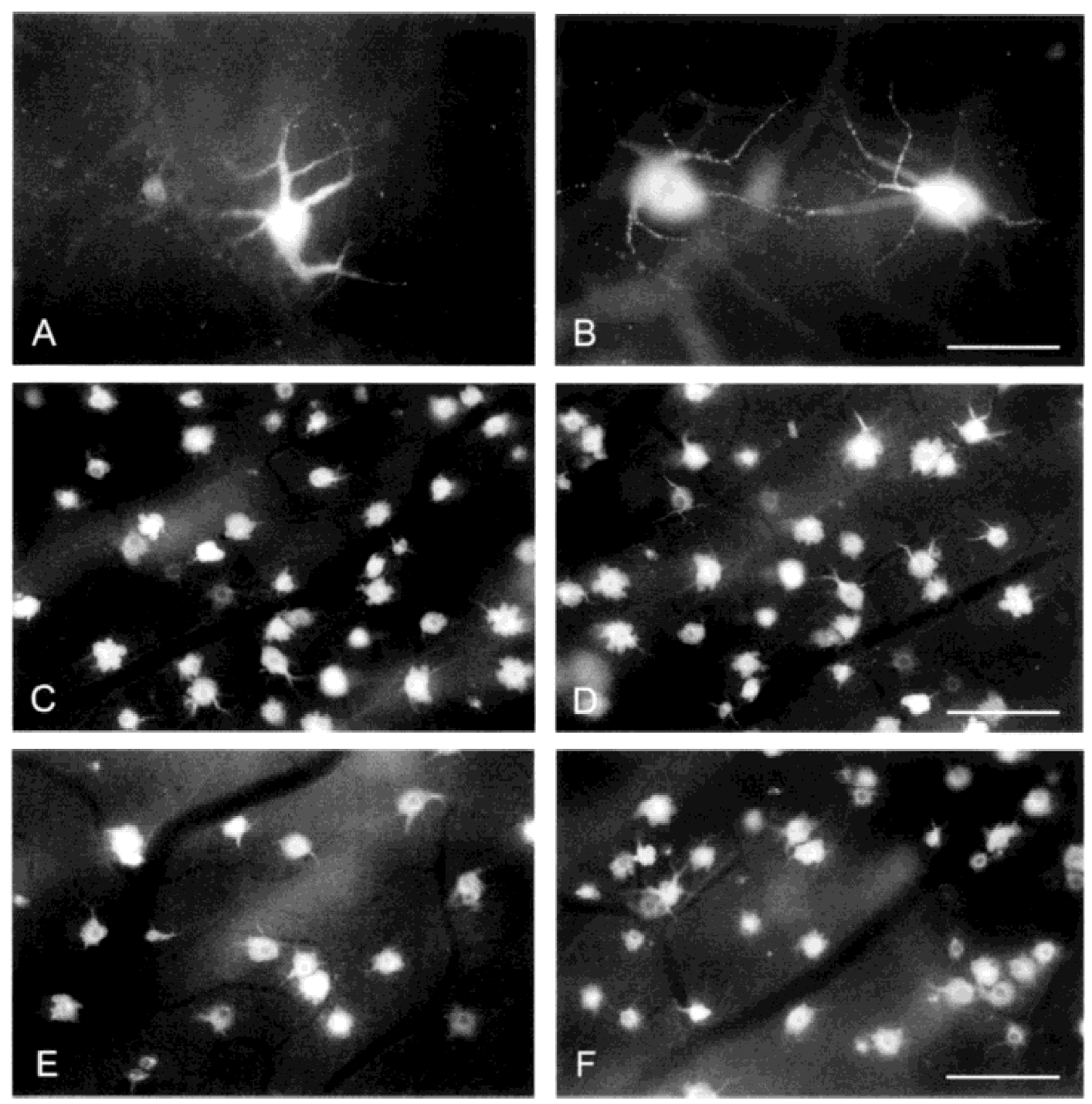

Fig. 2. General morphology of FG-labeled regenerating RGCs from an animal receiving the normal (A) or pre-degenerated (B) PN graft with the proximal ON pre-lesion 8 days before grafting. Enlarged cell bodies with simplified dendrites were observed. Similar numbers of regenerating RGCs were obtained in the control animals with the normal (C) and pre-degenerated (D) PN grafts. Fewer regenerating RGCs were detected in the normal (E) than in the pre-degenerated (F) PN graft subgroups at 2-day delay-time point in animals with the distal ON pre-lesion. Calibration $=50 \mu \mathrm{m}(\mathrm{A} \& \mathrm{~B})$ and $100 \mu \mathrm{m}(\mathrm{C}-\mathrm{F})$.

PN grafts, respectively; $P=0.0001), 4(677 \pm 226$ and $1215 \pm 67$ $P=0.0002)$, and $8(501 \pm 57$ and $1032 \pm 202 ; P=0.0001)$ days than the normal PN graft (Fig. 3B).

With the delay-time of 2 days, no significant difference in the number of regenerating RGCs was detected between the proximal and distal ON pre-lesions in animals with either the normal $(1116 \pm 557$ and $854 \pm 149$ for the proximal and distal ON pre-lesions, respectively; $P=0.2911$ ) or pre-degenerated (1688 \pm 319 and $1598 \pm 259 ; P=0.6015)$ PN graft. However, a dramatic drop in the number of regenerating RGCs was encountered at the 8-day time point in animals with the proximal ON pre-lesion as compared to the distal ON pre-lesion in both the normal $(239 \pm$ 104 and $501 \pm 57$ for the proximal and distal ON pre-lesions, respectively; $P=0.0003)$ and pre-degenerated $(293 \pm 161$ and $1032 \pm 202 ; P<0.0001$ ) PN graft subgroups (Fig. 4).

\section{Discussion}

In the present study, we have found that (1) unlike the findings in lower vertebrates and mammalian peripheral nervous system (PNS), pre-lesion to the ON has an adverse effect on axonal regeneration into a PN graft even though the delay between the ON pre-lesion and PN grafting was shortened to only 2 days; (2) the adverse effect increased when the delay-time was increased; (3) the adverse effect became more severe when the pre-lesion was made close to the RGC somata in comparison with that further away from the optic disc; and 4) this adverse effect can be overcome, to some degree, by a pre-degenerated rather than normal PN grafts. Thus, our hypothesis that a shortened time delay between the pre-lesion and the grafting might improve axonal regeneration of RGCs was not supported by our data. 


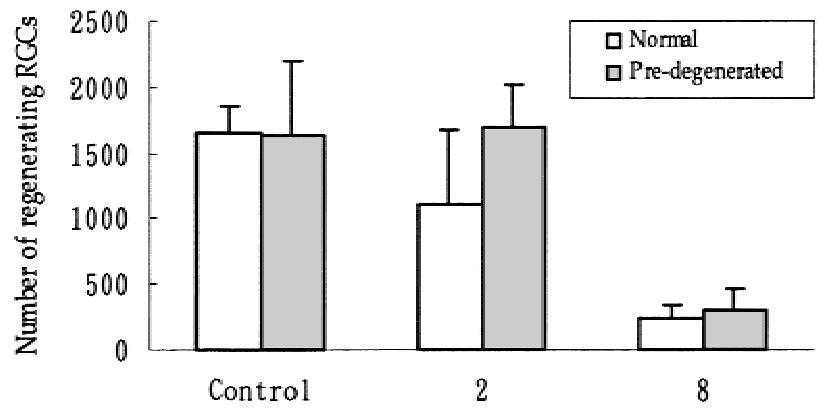

A. Delay (day) between the proximal ON pre-lesion and PN grafting

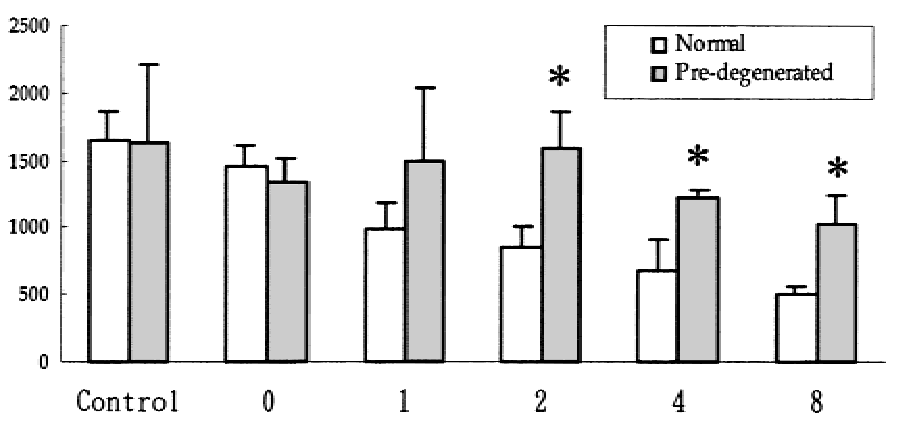

B. Delay (day) between the distal ON pre-lesion and PN grafting

Fig. 3. Histograms illustrating the mean numbers of RGCs regenerating their axons into a normal or pre-degenerated PN graft in Groups 2 and 3. (A) In the proximal ON pre-lesion group (Group 2), the number of regenerating RGCs declined in both the normal and pre-degenerated PN graft subgroups when the delay-time increased from 2 days to 8 days. (B) In Group 3 animals with the distal ON pre-lesion, the number of regenerating RGCs also decreased with the increase of the delay-time from 0 day to 8 days. Asterisks at 2-, 4-, and 8-day delay-time points indicate the numbers which are significantly different between the animals with the normal and pre-degenerated PN grafts. Error bars $=$ SD.

Axonal regeneration can be accelerated by an initial or conditioning lesion in the PNS axons of rodents (McQuarrie et al., 1977; McQuarrie, 1978; Wells \& Bernstein, 1978) and the optic axons of lower vertebrates (Brock, 1978; Lanners \& Grafstein, 1980; McQuarrie \& Grafstein, 1981; Reich et al., 1990). These axons have been shown to regenerate vigorously following a single axotomy. In adult rodents, however, a pre-lesion to the ON does not change the number of regrowing optic axons in the PN graft (Thanos \& Vanselow, 1989) although the initial delay for regrowth into a PN graft is reduced by a concurrent or delayed crush lesion of the $\mathrm{ON}$ (Cho \& So, 1989; Thanos \& Vanselow, 1989; So \& Yip, 2001). For the PNS, the enhancement of axonal outgrowth caused by an initial or conditioning delayed lesion does not depend upon changes at the site of the lesion or along the path of the growing axons. The effects of a conditioning lesion must therefore be due to a response of the cell body (Grafstein \& McQuarrie, 1978). The reduction in neurofilaments in the proximal axons of neurons after a delayed lesion has been shown to reduce the interference of tubulin transport (Tetzlaff et al., 1996). This may allow more tubulin to be transported more rapidly into the growing axon, to support the faster elongation rate of conditioned axons following the second lesion. It was also suggested that the enhanced outgrowth resulting from a conditioning lesion is due to a transient increase in the amount of fast transport. Such an increase may be responsible for a decreased delay in the initiation of sprouting. A sustained increase in the amount and velocity of slow transport may also account for an increased rate of elongation (McQuarrie \& Grafstein, 1982). These alterations are considered to be important in priming PNS neurons with conditioning axonal lesions for regeneration. However, such metabolic activity cannot be induced by a

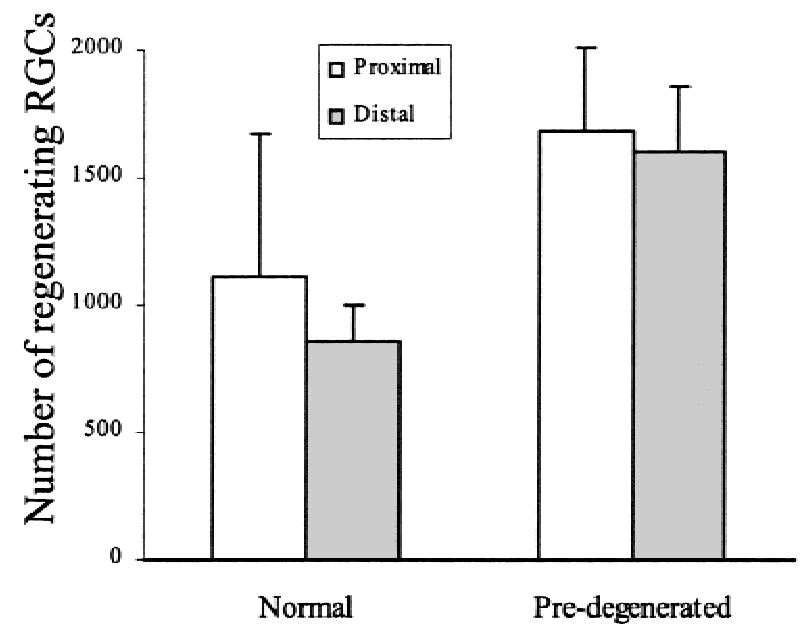

\section{A. Delay-time (2 days)}

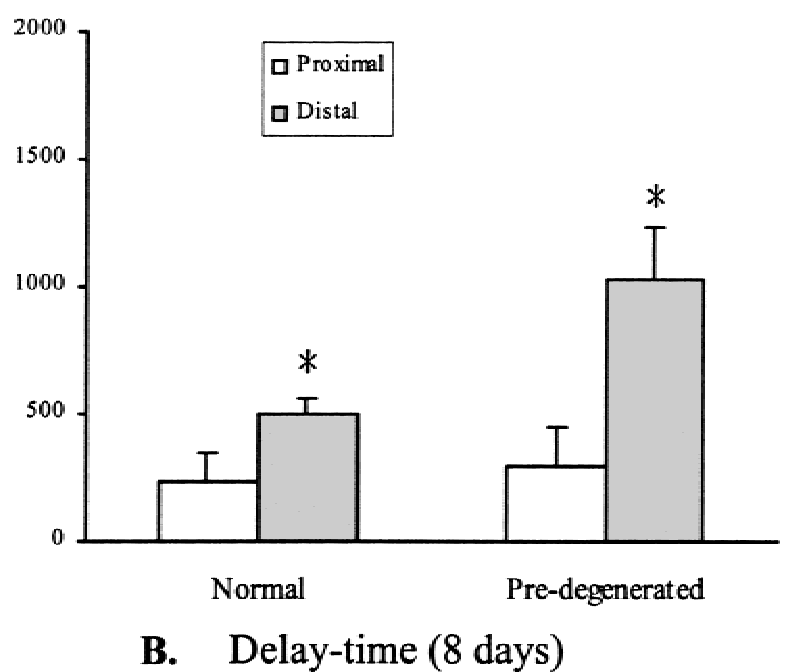

Fig. 4. Histograms illustrating the mean numbers of RGCs regenerating their axons into a normal or pre-degenerated PN graft in the distal and proximal ON pre-lesion groups. No significant difference was found between animals receiving the proximal and distal ON pre-lesion with the delay-time of 2 days (A). At the 8-day delay-time point, the mean numbers of regenerating RGCs were significantly different between the distal and proximal ON pre-lesion animals with a normal or pre-degenerated PN graft (B). 
similar lesion in adult mammalian CNS neurons (McKerracher et al., 1993a,b). The intrinsic growth potential of CNS neurons and their extraneuronal microenvironment limit the regenerating capacity of injured CNS neurons. The lack of Schwann cells in the mammalian CNS may preclude the long-term survival of axotomized RGCs that become destined for axonal degeneration and cell death following injury.

ON pre-lesions made at different distances from the cell bodies (proximal or distal) also exerted varying effects on regeneration in the present study. It has been well documented that although many RGCs can be induced to regenerate their damaged axons into a PN graft if the axotomy is performed close to their cell bodies (So \& Aguayo, 1985; Berry et al., 1986; Vidal-Sanz et al., 1987; Watanabe et al., 1991; Cho \& So, 1993; You et al., 2000; So \& Yip, 2001), very few will do so following intracranial axotomy (Richardson et al., 1982; Stevenson, 1985; Lau et al., 1994; $\mathrm{Ng}$ et al., 1995; You et al., 2000). Axonal regeneration has been thought to be due to the upregulation of genes (such as GAP-43 and c-Jun) in injured neurons, and upregulation of these genes have been demonstrated following proximal than after distal axotomy (Doster et al., 1991; Ng et al., 1992; Zeng et al., 1992; Hull \& Bähr, 1994). Therefore, the lack of the ability of the ON pre-lesion to promote axonal regeneration may be due to the longer distance of the distal ON pre-lesion from the somata of RGCs. However, in our experiments a similar number of regenerating RGCs was found in animals with a proximal ON pre-lesion (Group 2) carried out 2 days before grafting when compared to those with the distal ON pre-lesion (Group 3) at the same delay-time point. In addition, when animals with a proximal or distal ON pre-lesion 8 days before grafting were compared, the number of regenerating RGCs decreased significantly in animals with the proximal ON pre-lesion (Group 2). Thus, the proximal ON pre-lesion caused a greater deterioration in the capacity of RGCs to regenerate their axons. These phenomena may be explained by the time course of RGC loss following axotomy. No change in the number of surviving RGCs can be detected 2 days after either intraorbital or intracranial ON transection. RGC loss occurs earlier and is more severe 8 days after intraorbital rather than intracranial ON transection (Berkelaar et al., 1994). The higher incidence of neuronal death of RGCs may be the cause for the smaller number of regenerating RGCs detected in animals with the proximal ON lesion 8 days before grafting. As neither the distal nor proximal ON pre-lesion could enhance axonal regeneration of RGCs with shortened delay-time, the adverse effects of the pre-lesion of adult mammalian ON may be related either to the inherent properties of the neurons or to the nonneuronal elements that inhibit axonal regeneration in most parts of the mammalian CNS (Caroni \& Schwab, 1988; Mukhopadhyay et al., 1994; Chen et al., 2000), or to the inherent immune response in the CNS following injury (Schwartz et al., 1999).

Whether or not a pre-degenerated PN graft can enhance the axonal regeneration of axotomized RGCs still remains controversial (Bähr et al., 1992; Thanos \& Mey, 1995; You et al., 2000). A pre-crushed PN graft significantly enhances more RGCs to survive and regenerate in comparison with a normal PN graft 3 months after transplantation (Bähr et al., 1992). However, a similar precrushed PN segment cannot increase the number of regenerating RGCs 2 months after grafting (Thanos \& Mey, 1995). As for our previous study, a pre-crushed PN graft induces more RGCs to regenerate than a normal or pre-transected $\mathrm{PN}$ graft 4 weeks after grafting (You et al., 2000). In the present study, the use of a pre-transected PN graft reduced the adverse effect of an ON pre-lesion only at 2-, 4-, and 8-day delay-time points since more regenerating RGCs could be observed when compared to animals with the normal PN grafts in Group 3 animals with the distal ON pre-lesion. Our results indicated that a pre-degenerated PN graft can exert the promoting effect on axonal regeneration within a specific and limited range. Although the precise mechanism for the beneficial effects of a pre-degenerated nerve graft is not fully known, the proliferation of Schwann cells and removal of some potent inhibitors of neurite growth may be responsible for most of the observed effects. Severance or crush of peripheral nerves results in Wallerian degeneration of the distal axonal processes. During Wallerian degeneration of the distal nerve segment to be used as a PN graft, Schwann cells proliferate and infiltrating macrophages remove axonal and myelin debris (Perry et al., 1987) and presumably myelin-associated glycoprotein (MAG), a major myelin-derived growth inhibitor of neurite growth from adult neurons (McKerracher et al., 1994; Mukhopadhyay et al., 1994) normally present in PN myelin internodes. Schwann cells are involved in the synthesis of a variety of diffusible trophic factors such as nerve growth factor (Heumann et al., 1987), brain-derived neurotrophic factor (Meyer et al., 1992), ciliary neurotrophic factor (Rende et al., 1992), interleukin-6 (Bolin et al., 1995), and insulin-like growth factor-1 (Kanje et al., 1989). In addition, the ability of Schwann cells to foster axonal regeneration involves various extracellular molecules, including L1 (Seilheimer \& Schachner, 1988), N-Cadherin (Letourneau et al., 1990), neural cell adhesion molecules (Bixby et al., 1988), and heparan sulphate proteoglycan complex (Sandrock \& Matthew, 1987). These changes are thought to create a favorable microenvironment for axonal regeneration. However, it seems that such a beneficial microenvironment only had a limited ability of enhancing axonal regeneration as no significant differences were detected in control animals and the animals with the proximal ON pre-lesion and with the distal ON pre-lesion at 0- and 1-day time points. For control animals and animals with the distal ON pre-lesion at 0 - and 1-day time points, a normal PN graft would be sufficient to support the maximum axonal regeneration after a relatively mild $\mathrm{ON}$ injury in these animals. But for a rather severe proximal ON pre-lesion, even an increased amount of trophic factors and decreased inhibitor of neurite growth in a pre-degenerated PN graft could not enhance more axotomized RGCs to survive and regenerate as compared with a normal PN segment.

In conclusion, our results show that a pre-lesion of the optic nerve in hamsters, either close or far away from the optic disc, does not promote axonal regeneration even though the interval between the ON pre-lesion and PN grafting is shortened to only 2 days. Our hypothesis that a shortened time delay between the pre-lesion of the $\mathrm{ON}$ and the grafting of a PN might improve RGC axonal regeneration in adult hamsters is not supported by our results. These findings differ from previous demonstrations showing that pre-lesions increase axonal regeneration in the PNS and CNS of goldfish and amphibians. The use of a pre-degenerated PN graft can overcome some of the adverse effect after a distal ON pre-lesion. Thus, our results suggest an important practical finding that intervention of a pre-degenerated PN graft to promote RGC axon regeneration should be made immediately after the ON lesion.

\section{Acknowledgments}

This study was supported by the grants from Research Grant Council and the University of Hong Kong, and the National Natural Foundation of China (\#30070799). The authors thank Dr. Sheng-Xiu Li for his help in the statistical analysis and Dr. Margaret Tan for her comments on the manuscript. 


\section{References}

Bähr, M., Eschweiler, G.W. \& Wolburg, H. (1992). Precrushed sciatic nerve grafts enhance the survival and axonal regrowth of retinal ganglion cells in adult rats. Experimental Neurology 116, 13-22.

Berkelaar, M., Clarke, D.B., Wang, Y.C, Bay, G.M. \& Aguayo, A.J. (1994). Axotomy results in delayed death and apoptosis of retinal ganglion cells in adult rats. Journal of Neuroscience 14, 43684374.

Berry, M., Rees, L. \& Sievers, J. (1986). Unequivocal regeneration of rat optic nerve axons into sciatic nerve isografts. In Regeneration of Optic Nerve Axons, ed. Das, G.D. \& Wallace, R.B., pp. 63-79. New York: Springer-Verlag.

Bixby, J.L., LiLIEN, J. \& Reichardt, L.F. (1988). Identification of the major proteins that promote neuronal process outgrowth on Schwann cells in vitro. Journal of Cell Biology 107, 353-361.

Bolin, L.M., Verity, A.N., Silver, J.E., Shooter, E.M. \& Abrams, J.S. (1995). Interleukin-6 production by Schwann cells and induction in sciatic nerve injury. Journal of Neurochemistry 64, 850-858.

Brock, T.O. (1978). The effect of repeated nerve injury on regenerative repair in the optic nerve of the newt, Trirurus viridescens. Anatomical record 190, 349.

Caroni, P. \& Schwab, M.E. (1988). Antibody against myelin-associated inhibitor of neurite growth neutralizes nonpermissive substrate properties of CNS white matter. Neuron 1, 85-96.

Chen, M.S., Huber, A.B., van der Haar, M.E., Frank, M., Schnell, L., Spillmann, A.A., Christ, F. \& Schwab, M.E. (2000). Nogo-A is a myelin-associated neurite outgrowth inhibitor and an antigen for monoclonal antibody IN-1. Nature 403, 434-439.

CHo, E.Y. \& So, K.-F. (1987). Rate of regrowth of damaged retinal ganglion cell axons regenerating in a peripheral nerve graft in adult hamsters. Brain Research 419, 369-374.

Cно, E.Y. \& So, K.-F. (1989). Regrowth of retinal ganglion cell axons into a peripheral nerve graft in the adult hamster is enhanced by a concurrent optic nerve crush. Experimental Brain Research 78, 567-574.

CHо, E.Y. \& So, K.-F. (1993). Sprouting of axon-like processes from axotomized retinal ganglion cells is influenced by the distance of axotomy from the cell body and the mode of transplantation of the peripheral nerve. Restorative Neurology and Neuroscience 6, 29-34.

Doster, S.K., Lozano, A.M., Aguayo, A.J. \& Willard, M.B. (1991). Expression of the growth-associated protein GAP-43 in adult rat retinal ganglion cells following axon injury. Neuron 6, 635-647.

Edwards, D.L., Alpert, R.M., Mandelson, P.G., McQuarrie, I.G. \& Grafstein, B. (1979). Enhancement of axonal outgrowth by a prior ("Conditioning") lesion: Effect of lesion interval. Society for Neuroscience Abstracts 5, 676.

Forman, D.S., McQuarrie, I.G., Labore, F.W., Wood, D.K., Stone, L.S., Braddock, C.H. \& Fuchs, DA. (1980). Time course of the conditioning lesion effect on axonal regeneration. Brain Research 182, $180-185$.

Grafstein, B. \& McQuarrie, I.G. (1978). Role of the nerve cell body in axonal regeneration. In Neuronal Plasticity, ed. Cotman, C.W., pp. 155195. New York: Raven.

Hasan, N., Neumann, M.M., DeSouky, M.A., So, K.-F. \& Bedi, K.S. (1996). The influence of predegenerated nerve grafts on axonal regeneration from prelesioned peripheral nerves. Journal of Anatomy 189, 293-302.

Heumann, R., Korsching, S., Bandtlow, C. \& Thoenen, H. (1987). Changes of nerve growth factor synthesis in non-neuronal cells in response to sciatic nerve transection. Journal of Cell Biology 104, $1623-1632$.

Hull, M. \& B̈̈HR, M. (1994). Differential regulation of c-JUN expression in rat retinal ganglion cells after proximal and distal optic nerve transection. Neuroscience Letters 178, 39-42.

Kanje, M., Skottner, A., SJoberg, J. \& Lundborg, G. (1989). Insulinlike growth factor 1 (IGF-1) stimulates regeneration of the rat sciatic nerve. Brain Research 486, 396-398.

Kiernan, J.A. (1985). A conditioning lesion does not induce axonal regeneration in the optic nerve of the rat. Experimental Neurology 87, $181-184$.

Lanners, H.N. \& Grafstein, B. (1980). Effect of a conditioning lesion on regeneration of goldfish optic axons: Ultrastructural evidence of enhanced outgrowth and pinocytosis. Brain Research 196, 547-553.

LAU, K.C., So, K.-F. \& TAY, D. (1994). Intravitreal transplantation of a segment of peripheral nerve enhances axonal regeneration of retinal ganglion cells following distal axotomy. Experimental Neurology 128, 211-215.

Letourneau, P.C. Shattuck, T.A., Roche, F.K., Takeichi, M. \& LemMON, V. (1990). Nerve growth cone migration onto Schwann cells involves the calcium-dependent adhesion molecule, N-cadherin. Developmental Biology 138, 430-442.

McKerracher, L., Essagian, C. \& Aguayo, A.J. (1993a). Temporal changes in beta-tubulin and neurofilament mRNA leveos after transection of adult rat retinal ganglion cell axons in the optic nerve. Journal of Neuroscience 13, 2617-2626.

McKerracher, L., Essagian, C. \& Aguayo, A.J. (1993b). Marked increase in beta-tubulin mRNA expression during regeneration of axotomized retinal ganglion cells in adult mammals. Journal of Neuroscience 13, 5294-5300.

McKerracher, L., David, S., Jackson, D.L., Kottis, V., Dunn, R.J. \& BraUn PE. (1994). Identification of myelin-associated glycoprotein as a major myelin-derived inhibitor of neurite growth. Neuron 13, 805-811.

McQuarRIE, I.G. (1978). The effect of a conditioning lesion on the regeneration of motor axons. Brain Research 152, 597-602.

MCQUARRIE, I.G. \& GRAFSTEIN, B. (1981). Effect of a conditioning lesion on optic nerve regeneration in goldfish. Brain Research 216, 253-264.

McQuarrie, I.G. \& Grafstein, B. (1982). Protein synthesis and axonal transport in goldfish retinal ganglion cells during regeneration accelerated by a conditioning lesion. Brain Research 251, 25-37.

McQuarrie, I.G., Grafstein, B. \& Gershon, M.D. (1977). Axonal regeneration in the rat sciatic nerve: Effect of a conditioning lesion and of dbcAMP. Brain Research 132, 443-453.

McQuarrie, I.G., Grafstein, B., Dreyfus, C.F. \& Gershon, M.D. (1978). Regeneration of adrenergic axons in rat sciatic nerve: Effect of a conditioning lesion. Brain Research 141, 21-34.

Meyer, M., Matsuoka, I., Wetmore, C., Olson, L. \& Thoenen, H. (1992). Enhanced synthesis of brain-derived neurotrophic factor in the lesioned peripheral nerve: Different mechanisms are responsible for the regulation of BDNF and NGF mRNA. Journal of Cell Biology 119, $45-54$.

Mukhopadhyay, G., Doherty, P., Walsh, F.S., Crocker, P.R. \& Filbin, M.T. (1994). A novel role for myelin-associated glycoprotein as an inhibitor of axonal regeneration. Neuron 13, 757-767.

NG, T.F., So, K.-F. \& Chung, S.K. (1992). Enhanced expression of GAP-43 in retinal ganglion cells by an intravitreous peripheral nerve graft after intraorbital axotomy in hamsters. Society for Neuroscience Abstracts 22, 426.

NG, T.F., So, K.-F. \& Chung, S.K. (1995). Influence of peripheral nerve grafts on the expression of GAP-43 in regenerating retinal ganglion cells in adult hamsters. Journal of Neurocytology 24, 487-496.

Perry, V.H., Brown, M.C. \& Gordon, S. (1987). The macrophage response to central and peripheral nerve injury. A possible role for macrophages in regeneration. Journal of Experimental Medicine 165, $1218-1223$.

Reich, J.B., Burmeister, D.W., Schmidt, J.T. \& Grafstein, B. (1990). Effect of conditioning lesions on regeneration of goldfish optic axons: Time course of the cell body reaction to axotomy. Brain Research 515, 256-260.

Rende, M., Muir, D., Rouslahti, E., Hagg, T., Varon, S. \& ManTHORPE, M. (1992). Immunolocalization of ciliary neurotrophic factor in adult rat sciatic nerve. Glia $\mathbf{5}, 25-32$.

Richardson, P.M., Issa, V.M.K. \& Shemie, S. (1982). Regeneration and retrograde degeneration of axons in the rat optic nerve. Journal of Neurocytology 11, 949-966.

SANDROCK, A.W. \& MATTHEW, W.D. (1987). Identification of a peripheral nerve neurite growth-promoting activity by development and use of an in vitro bioassay. Proceedings of the National Academy of Sciences of the U.S.A. 84, 6934-6938.

Schwartz, M., Moalem, G., Leibowitz-Amit, R. \& Cohen, I.R. (1999). Innate and adaptive immune responses can be beneficial for CNS repair. Trends in Neurosciences 22, 295-299.

Seilheimer, B. \& Schachner, M. (1988). Studies on adhesion molecules mediating interactions between cells of peripheral nervous system indicate a major role for L1 in mediating sensory neuron growth on Schwann cells in culture. Journal of Cell Biology 107, 341-351.

So, K.-F. \& Aguayo, A.J. (1985). Lengthy regrowth of cut axons from ganglion cells after peripheral nerve transplantation into the retina of adult rats. Brain Research 328, 349-354.

So, K.-F. \& YIP, H.K. (2001). The use of peripheral nerve transplants to enhance axonal regeneration in CNS neurons. In Axonal Regeneration 
in the Central Nervous System, ed. Ingoglia, N.A. \& Murray M., pp. 505-528. New York: Marcel Dekker, Inc.

SteVenson, J.A. (1985). Growth of optic tract axons in nerve grafts in hamster. Experimental Neurology 87, 446-457.

Tetzlaff, W., Leonard, C., Krekoski, C.A., Parhad, I.M. \& Bisby, M.A. (1996). Reductions in motoneuronal neurofilament synthesis by successive axotomies: A possible explanation for the conditioning lesion effect on axon regeneration. Experimental Neurology 139, 95106.

Thanos, S. \& VANSElow, J. (1989). Adult retinal ganglion cells retain the ability to regenerate their axons up to several weeks after axotomy. Journal of Neuroscience Research 22, 144-149.

Thanos, S. \& MeY J. (1995). Type-specific stabilization and targetdependent survival of regenerating ganglion cells in the retina of adult rats. Journal of Neuroscience 15, 1057-1079.

Vidal-Sanz, M., Bray, G.M., Villegas-Perez, M.P., Thanos, S. \& Aguayo, A.J. (1987). Axonal regeneration and synapse formation in the superior colliculus by retinal ganglion cells in the adult rats. Journal of Neuroscience 7, 2894-2909.

Watanabe, M., Sawai, H. \& Fukuda, Y. (1991). Axonal regeneration of retinal ganglion cells in the cat geniculocortical pathway. Brain Research 560, 330-333.

Wells, M.R. \& BeRnsteIn, J.J. (1978). Amino acid incorporation into rat spinal cord and brain after simultaneous and interval sciatic nerve lesions. Brain Research 139, 249-262.

You, S.-W., So, K.-F., YiP, H.K. \& BedI, K.S. (1996). Effect of a pre-degenerated peripheral nerve graft and a conditioning lesion of optic nerve on axonal regeneration of retinal ganglion cells. Society for Neuroscience Abstracts 22, 1230.

You, S.-W., So, K.-F. \& YIP, H.K. (2000). Axonal regeneration of retinal ganglion cells depending on the distance of axotomy in adult hamsters. Investigative Ophthalmology and Visual Science 41, 3165-3170.

Zeng, B.Y., ANDERSON, P.N., CAMPBell, G., Lieberman, A.R. \& Schreyer, D.J. (1992). GAP-43 in retinal ganglion cells of the adult rat after intraorbital and intracranial axotomy. Neuroscience Letters (Suppl.) 42, S19.

Zeng, B.Y., Anderson, P.N., Campbell, G. \& Lieberman, A.R. (1995). Regenerative and other responses to injury in the retinal stump of the optic nerve in adult albino rats: Transection of the intracranial optic nerve. Journal of Anatomy 186, 495-508. 